\title{
Growth Determinants of Small Medium Enterprises (SMEs)
}

\author{
Endi Sarwoko*, Christea Frisdiantara \\ Faculty of Economics and Business, Kanjuruhan University, Indonesia
}

Copyright $(2016$ by authors, all rights reserved. Authors agree that this article remains permanently open access under the terms of the Creative Commons Attribution License 4.0 International License

\begin{abstract}
Small Medium Enterprises (SMEs) are still an issue that is interesting to study because it is recognized that small businesses have a major role in employment and contribution to the gross domestic product. Previous research shows that the growth of SMEs is determined by the owner/manager characteristics (personal approach), and how the strategy is taken (managerial approach). This study empirically tested the three determinants of growth of small businesses, namely 1) the individual factors 2) organizational factors, and 3) environment factors. The study was conducted in SMEs assisted in the district of Malang, using a sample of 52 owners/managers of SMEs, which are taken by purposive sampling, analysis techniques using Path Analysis. The results showed that individual factors directly affects the growth of the business, as well as an indirect effect through organizational factors. So the individual factors are a determinant of the growth of SMEs, due to individual factors which reflected the business experience and the motivation of the owners/managers will be able to manage the organization becomes more effective so as to compete, and the effects are on the achievement of business growth. Environmental factors provide the greatest impact in achieving the growth of SMEs, it means the ability of owner/managers to produce competitive products, leverage technology, and diversity of products will determine the growth of SMEs.
\end{abstract}

Keywords Business Growth, Individual Factors, Organizational Factors, Environment Factors

\section{Introduction}

Small and medium enterprises (SMEs) have a role that contributed to the gross domestic product and employment, but the fact that the success of SMEs is still low, one indicator is the percentage of small and medium enterprises that have succeeded in penetrating export markets and export potential is still relatively low compared to total existing SMEs. This phenomenon needs to be answered by knowing the factors determining the growth of SMEs. So the results of this study are expected to contribute to the government in the formulating policy on SMEs development in Malang..

Studies on the business performance of small and medium enterprises can be classified into two groups which focus on personal and the organizational aspect. The aspects of personality, such as individual characteristics, demographic, and competencies. While the study of organizational aspects includes the resources of the organization, the company's competence, organizational culture, and structure (Sarwoko, [17]).

Growth determinants of small businesses can be classified in many factors: individual, organizational, and environmental (Zhou and Wit, [22]), factor of organizational resources, the competence of the company, organizational culture and structure (Covin \& Slevin, [5]), competency of individuals in the entrepreneurial process $(\mathrm{Li},[10])$, the owners/managers characteristics and strategies (Nimalathasam, [15]; Sarwoko, [17]).SMEs performance is determined by the owner/manager characteristics and entrepreneurial competence (Sarwoko, [17]). Entrepreneurial competence will determine the strategy on the performance of SMEs (Sarwoko, [18]). These findings show the importance of the individual factors as determinants of the growth of SMEs.

Although several studies have analyzed the determinants of business growth, but each factor analyzed separately, which only focus on personal factors, organizational factors, as well as strategies (Baum, Locke and Smith, [3]; Covin \& Slevin, [5], Delmar et al., [6]). The environment is a factor that also influences the growth of SMEs because growth is uncertain, due to environmental conditions such as competitive conditions and changing market dynamics. Therefore, it is necessary to examine the determinants of SMEs growth are more complex into three dimensions, namely individual, the organization and the environment.

\section{Literature Review}

Previous research has found that the attitude and the ability of owners/manager have an important impact on the growth of small enterprises and will be reflected in the 
strategic choices and the ways in which it operates the business (Sarwoko, [17]; Covin \& Slevin, [5]; Li, [10]; Nimalathasam, [15]).

Business growth is determined by several factors: individual characteristics, organizational characteristics, relationships and environmental characteristics, strategy development and planning, as well as organizational development (Street \& Cameron, [21]). Business growth is determined by the personal value of the owner/manager and strategy, where personal values will influence the strategy chosen by the owner/manager (Street \& Cameron, [21]).

\section{Individual Determinants}

Personality traits an entrepreneur, motivational growth, individual competence and personal background are the most important determinants that determine the growth of SMEs (Baum et al, [3]; Delmar, [6]; Shane et al., [19]). Blackman [5] divides the characteristics of an entrepreneur into two types, namely:

\section{Attribute}

The attributes are characteristic that is in itself an entrepreneur includes age, gender, religion, the influence of family (family influence).

\section{Attained}

Attained include education and experience of the owner/manager.

Entrepreneur character is influenced by several internal and external factors, namely the family, education, personal values, and work experience (Shane, [19]).

\section{Organization Determinants}

The growth of SMEs can be determined by the effectiveness and capabilities of the company's resources such as labor, capital and knowledge acquired, organized and transformed into products and services through the activities of the organization, practices and structures (Nickell, [13]; Nickell et al. [14).

The determining factors are often discussed in previous studies from various disciplines (Zhou and Wit, [22]), among others:

1. Firm attributes

2. Firm strategies

3. Firm-specific resources

4. Organizational structure

5. Dynamic capability

\section{Environmental Determinants}

Most SMEs start and grow, but it is easy to fall due to competition. One major reason is that most of them start businesses that are imitative in mature industries that serve the local market (Audretsch and Mahmood, [1]; Baldwin and Gellatly, [2]). Environmental factors in this competition are a factor causing small businesses to grow (Lindholm,
[11]). Determinants of the growth of SMEs can be identified as individual factors, organizational factors, and environmental factors (Zhou and Wit, [22]).

Based on the literature review and previous studies the factors that affect the growth of small and medium enterprises can be identified individual factors, organizational factors, and environmental factors (Baum, [3]). Organizational influenced the competence and knowledge of the owner / manager. Strategy and strategic vision make a clear direction for the company and an important factor in the company's policy in decision-making (Philipsen and Kemp, [16]), meaning that individual factors (competences and knowledge) play an important role in management decision making.Entrepreneurial competence plays a key role in determining the performance of SMEs. Entrepreneurial competence plays a key role in determining the performance of SMEs. Entrepreneurial competence will also affect the ability of the organization, then the organization's ability constituting the decoding performance of SMEs (Man et al., [12]).

This study adopted the concept Baum, that the determinant of the growth of SMEs is a combination of individual factors, organizational factors, and environmental factors, which will be tested the influence of individual factors on organizational factors.

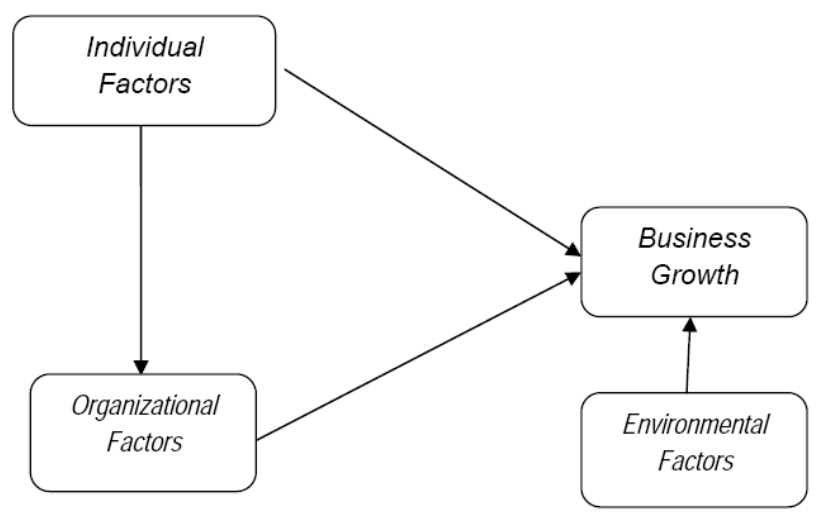

Figure 1. Conceptual Framework

\section{Method}

This research is an explanatory research, to analyze and explain the influence of individual factors, organizational factors, and the environment for business growth. Organizational factors as mediating variables used to examine the relationship of individual factors to the growth of the business. The study was conducted on startup small and medium enterprises in the district of Malang. Using purposing sampling method, with a sample of 52 SMEs.

The research variables include independent variablesare the individual factors, organizational factors, environmental factors, and the dependent variable of the research business growth adopted Zhou and Wit [22]. 
1. Individual Factors

The individual factors measured by indicators of personal traits, growth, motivation, individual competencies, and personal background.

2. Organizational Factors

Organizational factors measured by indicators of the attributes of the company, corporate strategy, corporate resources, and dynamic capability.

3. Environmental Factors

Environmental factors measured by indicators of market, technology, and diversity efforts.

\section{Business Growth}

Business growth is the perception of the owner/manager of the business performance compared to objectives. Growth measurements using indicators of Lee and Tsang [8] consist of 3 that growth in sales, profits, and capital.

Using descriptive analysis and path analysis to examine the direct and indirect relationship of individual factors and organizational factors on the growth of SMEs.

\section{Finding and Discussion}

\subsection{Variable}

Individual factors of the owners of SMEs supported by family background, education and experience in business management. Some indicators of individuals who contributed greatly among business people had the experience that is long enough to pursue his efforts, in addition, they have an average of motivation to succeed in business. Indicators of family support and educational background have a lower contribution than the experience and motivation. Indicators the highest individual factors which are owned by the owners of SMEs are business experience means that the experience has been the key to the success of small business owners so that they can compete with other SMEs.

Individual factors of the owners/managers come from a family background, education, and experience in the business. Some individual factors that contributed greatly among the businesses that have had a long experience to pursue his efforts, in addition, they on average have a great motivation to excel in business. Indicators highest individual factors which are owned by the owners of SMEs are business experience, means that the experience has been the key to the success of small business owners so that they can compete with other SMEs. Attributes companies and resources play a major role in supporting organizational factors. Several factors contribute to the organization that most of them are owned resource advantages, in particular, the availability of raw materials and skilled labor. The level of competition, technological excellence, and diversity of products is a factor which is an advantage for small business owners. This shows that SMEs have been able to grow and thrive because it is able to overcome the impact of the business environment.

Table 1. Descriptive Statistics

\begin{tabular}{clcc}
\hline $\begin{array}{c}\text { N } \\
\text { o. }\end{array}$ & Variabels and Indicators & Mean & $\begin{array}{c}\text { Standard } \\
\text { Deviation }\end{array}$ \\
\hline A & Individual Factors & 3.17 & 0.985 \\
1 & Family & 3.04 & 0.766 \\
2 & Education & 3.92 & 0.788 \\
3 & Experience & 3.90 & 0.774 \\
4 & Motivation & & \\
B & Organizational Factors & 3.04 & 0.839 \\
1 & Firm experience & 3.04 & 0.685 \\
2 & Firm Size & 3.79 & 0.750 \\
3 & Material resources & 3.92 & 0.710 \\
4 & Human resources & & \\
C & Environmental Factors & 3.81 & 0.715 \\
1 & Competition & 3.96 & 0.766 \\
2 & Technology & 3.54 & 0.803 \\
3 & Product diversification & & \\
D & Business Growth & 3.79 & 0.750 \\
1 & Sales growth & 3.92 & 0.710 \\
2 & Profit growth & 3.73 & 0.770 \\
3 & Capital growth & &
\end{tabular}




\subsection{Result}

Path analysis results can be explained in the following figure:

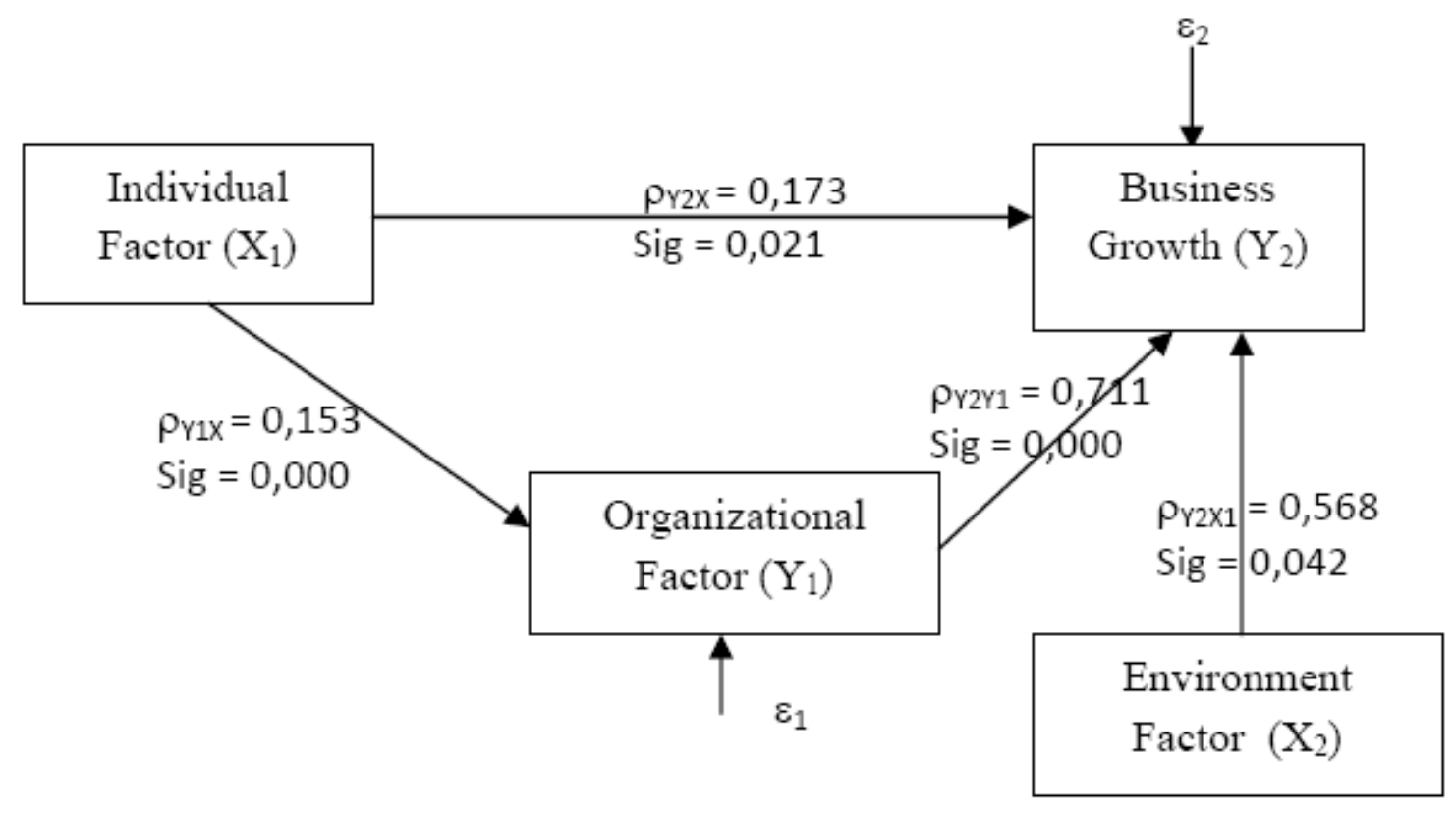

Figure 2. Parth Analysis

Figure 2 shows the direct and indirect effect of each variable on the growth of the business. Furthermore, to compare the direct and indirect influence of the existing path by multiplying the path coefficients at each track is formed, the highest coefficient is the greatest influence. Individual factors directly affect business growth with the path coefficient of 0.173 and a significance level of 0.021 . Organizational factor affects business growth with path coefficient 0.711 and a significance level 0,000 . Individual factor indirect affect business growth through organizational factor with the path coefficient $0,153 \times 0,711=0,109$. The individual factors have a greater direct influence on the growth of the business than the indirect effect is through organizational factors. Environmental factor affects business growth with the path coefficient of 0,568 with a significance level of 0,042 . Thus, the environmental factor greatest effect to business growth.

\subsection{Discussion}

\section{The Influence of Individual Factors on the Growth of SMEs}

The results showed that the growth of SMEs is determined by individual factors, which consist of a family background, education, business experience, and motivation for business growth. Individual factors that contributed greatly among owner / manager has had business experience, in addition, they have had great motivation to succeed in business. As for the support of family and educational background is considered not contribute greatly to the SMEs in business. This is due to each type of business has different characteristics, and the face competition business environment is different also, so it is not entirely the experience of family and educational background does not have a big role, but it is the experience and personal motivation of entrepreneurs.

If the role of family background, education, business experience, and motivation of entrepreneurs the higher the greater the contribution to business growth. The findings of this study are relevant to previous research that the characteristics of the entrepreneur, motivational growth, individual competencies, and personal background are the determinants of growth of a company (Baum et al., [3]; Shane et al., [19]; Zhou and Wit, [22], Sorensen, [20], Hisrich et al., [7], Sarwoko, [17])

\section{The Influence of Organizational Factor on the Growth SMEs}

The results showed that organizational factors have an influence on the growth of SMEs, which means the effective organization and the higher the ability of the company resources such as raw materials, labor will increase business growth. So in order to achieve the growth of SMEs, the owner / manager must be able to identify the sustainability of raw materials, and the availability of skilled labor at reasonable costs, capital and long effort doesn't guarantee the achievement of business growth. The findings are relevant to previous research that the organizational factor are the determinants of growth of a company (Nickkell, [13]; Zhou and Wit, [22]). Organizational factors which make a major contribution of which is owned resource advantages, in that it is the availability of raw materials and skilled labor. As for 
the long effort and size of capital considered less a role for small and medium businesses in ensuring the success of the business.

\section{The Influence of Individual Factor on Organizational}

This study showed that individual factors evidently determine the achievement of organizational effectiveness, meaning how the ability of owner/managers to take advantage of the experience and motivation in creating an effective organization that is able to compete with similar companies become a key factor in business growth. So individual experiences a knowledge that can be used for strengthening the organization through activities organized and structured (Nickkell, [13]; Zhou and Wit, [22]).

\section{The Influence of Environment Factor on Organizational Business Growth}

The environment also plays a role determining the growth of SMEs, competitive conditions, the use of technology, and diversity of products produced will determine the growth of SMEs. Business competition can not be avoided by businesses, therefore, the organization must be effective, need to utilize technology in order to be a more efficient activity, so as to produce a variety of items that are able to compete. The findings are relevant to previous research that the enviroenmental factor factor are the determinants of growth of a company (Lindholm, [11]; Zhou and Wit, [22])

So environmental factor is a key factor in achieving growth of SMEs, where the business actors who already have business experience or management capable of managing the organization become more effective in order to compete, so they can anticipate the ever-changing business environment. The owner / manager must have a high motivation, and not easily give up, in order to utilize the existing resources for the creation of business growth.

\section{Conclusions}

1. Individual factors have a direct influence on the growth of the business, individual factors include business experience and motivation, which means businesses with experience and motivation to be able to read the opportunities, have creative ideas to market changes, so that businesses can grow.

2. Organizational factors affect the growth of the business, which means that more effective means an organization's ability to run and manage enterprise resources such as raw materials, labor will achieve business growth since the company would operate more effectively and efficiently.

3. Individual factors affect the organization, meaning that the owner/manager experience will provide knowledge to employers to manage the company's effective, organized and structured so that businesses can grow.

4. Environmental factors are key factors for the growth of
SMEs, it means the ability of owner / managers to manage the company effectively to be able to anticipate changes in the business environment and competition, will affect business growth.

5. SME growth is also determined by environmental factors, required the owner's ability to cope with environmental change.

\section{REFERENCES}

[1] Audretsh D. B and Mamood, T,. Firm Selection and Industry Evolution: The Post Entry Performance of New Firm, Journal of Evolutionary Economics, 243-260.1994.

[2] Baldwin, J and Gellatly G, Innovation Strategies and Performance in Small Firm. Cheltenham, UK. Edwar Elgar. 2003.

[3] Baum, J.R., Locke, E.A., and Smith, K.G.A Multidimensional Model of Venture Growth, Academy of Management Journal, 44(2): 292-303. 2001

[4] Blackman, A.J., Entrepreneurs: Interrelationships between their characteristics, values, expectations, management practices and SME performance. School of Business Department of Management Griffith University, Gold Coast Campus. (Submitted in fulfilment of the requirements of the degree of Doctor of Philosophy). 2003.

[5] Covin, J.G., and Slevin, D.P. A conceptual model of entrepreneurship as firm behavior. Entrepreneurship: Theory and Practice, 16(1): 7-24.1991.

[6] Delmar, F., Davidson, \& Garner, W. Arriving at the High Growth Firm, Journal of Business Venturing, 189-216. 2003.

[7] Hisrich, R.D., Peter, M.P., and Shepherd, D.A., Entrepreneurship. Chriswan Sungkono and Diana Angelica, Kewirausahaan, Salemba Empat, Jakarta. 2008.

[8] Lee D.Y. and Tsang, E.W.K., The Effect of Entrepreneurial Personality, Background and Network Activities on Venture Growth, Journal of Management Studies, 38(4): 583-602.2001.

[9] Li, H., Zhang, Y. and Chan, T.S., Entrepreneurial Strategy Making and Performance in China's New Technology Ventures - The Contingency Effect of Environment and Firm Competence, Strategic Management Journal. 2005.

[10] Li, X., Entrepreneurial Competencies as an Entrepreneurial Distinctive: An Examination of the Competency Approach in Defining Entrepreneurs. Dissertations and Theses Collection. Institutional Knowledge at Singapore Management University. 2009.

[11] Lindholm Dahlstrand, A, University Knowledge Transfer and The Role of Spin-off, Commissioned paper for the OECD Conference on Fostering Entrepreneurship: The Role of Higher Education, Trento, Italy, June.2005.

[12] Man, T.W.Y., Lau, T. and Chan, K.F. The competitiveness of small and medium enterprises a conceptualization with focus on entrepreneurial competencies. Journal of Business Venturing. 17 (2), 2002, 123-142. 
[13] Nickell, S. Competition and corporate performance. Journal of Political Economy, 104: 724-746.1996.

[14] Nickell, S., Nicolitsas, D., \& Dryden, N. What makes firms perform well? European Economic Review, 41(3-5): 783-796.1997.

[15] Nimalathasan, B., A Relationship between Owner-Managers Characteristic and Business Performance, Les ET Scientia International Journal, Vol. XV, No. 1.2008.

[16] Philipsen, R.L.C., and Kemp, R.G.M. Capabilities for growth: Anexploratory study on medium-sizedfirms in the Dutch ICT services andlife sciences, EIM, Zoetermeer. 2003.

[17] Sarwoko, E., Surachman, and Armanu, Entrepreneurial Characteristics and Competency as Determinants of Business Performance in SMEs, IOSR Journal of Business and Management, Vol. 7 Issue 3. 2013.

[18] Sarwoko, E. and Frisdiantara, C, Entrepreneurial
Competencies in Gender and Education Perspective, Proceeding International Conference Economic Bisnis and Management (ICEBM 2014), Penang-Malaysia. 2014.

[19] Shane, S., Locke, E.A., and Collins, C.T., Entrepreneurial Motivation, Human Resources Management Review, 13: 25-279. 2003.

[20] Sørensen, J.B. \& Chang, P.M.Y., Determinants of Successful Entrepreneurship: A Review of the Recent Literature Determinants of Successful Entrepreneurship2006.

[21] Street, C.T and Cameron, A.F. External Relationships and the Small Business: A Review of Small Business Alliance and Network Research, Journal of Small Business Management, 45(2), 2007.

[22] Zhou, Haibodan Wit, Gerrit de, Determinants and Dimensions of Firm Growth, Scales (Scientific Analysis of Entrepreneurship and SMEs), 2002. 